\title{
Microdialysis Perfusion of 8-Hydroxy-2-(Di-n-Propylamino)Tetralin (8-OH-DPAT) in the Dorsal Raphe Nucleus Decreases Serotonin Release and Increases Rapid Eye Movement Sleep in the Freely Moving Cat
}

\author{
Chiara M. Portas, Mahesh Thakkar, Donald Rainnie, and Robert W. McCarley \\ Laboratory of Neuroscience, Department of Psychiatry, Harvard Medical School and Brockton VA Medical Center, \\ Brockton, Massachusetts 02401
}

In vivo microdialysis was used to analyze the role of dorsal raphe nucleus (DRN) neurons in regulating the sleepwaking cycle. Measurements of extracellular serotonin (5-HT) were made in the DRN of freely moving adult cats before and during microdialysis perfusion of 8-hydroxy-2-(di-npropylamino)tetralin (8-OH-DPAT), a selective $5-\mathrm{HT}_{1 \mathrm{~A}}$ receptor agonist, in artificial CSF. Behavioral state alterations were measured by simultaneous polygraphic recordings. During waking and artificial CSF perfusion of probes histologically localized to the DRN, extracellular $5-\mathrm{HT}$ was $4 \mathrm{fmol} / 7.5 \mu \mathrm{l}$ dialysate sample. With the addition of 8 -OH-DPAT $(10 \mu \mathrm{M}$ in artificial CSF) to the perfusate, 5-HT levels in the same state decreased $50 \%$, to $2 \mathrm{fmol} / \mathrm{sample}(\rho<0.01$ ), presumably through $5-\mathrm{HT}_{1 \mathrm{~A}}$ autoreceptor-mediated inhibition of serotonergic neural activity. Concomitantly, this 8-OH-DPAT perfusion produced a short latency, threefold increase in rapid eye movement (REM) sleep, from 10 to $30 \%$ of the total recorded time
( $\rho<0.05$ ), whereas waking was not significantly affected. In contrast, and suggesting DRN specificity, 8-OH-DPAT delivery through a probe in the aqueduct did not increase REM sleep but rather tended to increase waking and decrease slow wave sleep.

The data on REM sleep provide the first biochemically validated and direct evidence that suppression of DRN serotonergic activity increases REM sleep, and furnish a key complement to our laboratory's in vitro data indicating that mesopontine cholinergic neurons, a target of DRN projections, are inhibited by $5-\mathrm{HT}$. The $8-\mathrm{OH}$-DPAT-induced reduction of DRN $5-\mathrm{HT}$ is consistent with the hypothesis that the concomitant REM sleep disinhibition is mediated by DRN serotonergic projections to mesopontine cholinergic neurons, which other data implicate in REM sleep production.

Key words: 5-HT; dorsal raphe nucleus; 8-OH-DPAT; REM sleep; brainstem; microdialysis
Serotonin (5-HT) has been implicated in control of many behaviorally related neural systems, including those for sleep (Steriade and McCarley, 1990), sex (Meston and Gorzalka, 1992), aggression (Coccaro, 1992; Olivier and Mos, 1992), mood (Soubrie, 1988), thermoregulation (Myers, 1980), motor activity (Thornton, 1978; Williams and Amitia, 1981), feeding (Blundell, 1977; Nicolaidis, 1986), pain modulation (Le Bars, 1994), endocrine regulation (Montange and Calas, 1988), and learning and memory (McFntee and Crook, 1991). With respect to changes in discharge rates of presumptively serotonergic dorsal raphe nucleus (DRN) neurons, in vivo physiological recordings have shown that the most dramatic alteration is associated with sleep: there is a virtual cessation of discharge of the entire neuronal population as the animal approaches and enters the rapid eye novement (REM) phase of sleep (McGinty and Harper, 1976; Trulson and Jacobs, 1979; Cespuglio et al., 1981; Lydic et al., 1987). This inverse correlation with REM sleep quite early led to the suggestion that

Received Oct. 2, 1995; revised Jan. 17, 1996; accepted Jan. 22, 1996.

This work was supported by grants from the Department of Veterans Affairs and R37 MH39683 (R.W.M.). C.M.P. holds a B. B. Brodie Fellowship in Neurochemical Pharmacology (FIDIA Research Foundation), and R.W.M. is a Department of Veterans Affairs Medical Investigator. We thank Michael Gray and Paul Simpson of the VA Medical Center Animal Research Facility for providing care for the animals, and Drs. R. W. Greene and P. Shiromani for helpful discussions.

Correspondence should be addressed to Robert W. McCarley, Laboratory of Neuroscience, Department of Psychiatry 116A, Harvard Medical School and VA Medical Center, 940 Belmont Street, Brockton, MA 02401.

Copyright (C) 1996 Society for Neuroscience $0270-6474 / 96 / 162820-09 \$ 05.00 / 0$ serotonergic activity might suppress REM sleep. Together with evidence for a similar time course of activity of presumptively noradrenergic locus coeruleus neurons (Hobson et al., 1975), it led to the inclusion of monoaminergic, including serotonergic, inhibition of REM-promoting cholinergic neurons as a fundamental postulate of a structural and mathematical model of REM sleep (McCarley and Hobson, 1975). This postulate was originally regarded as extremely controversial. However, interest has been quickened by the following: the recent documentation of serotonergic projections from the dorsal raphe to the mesopontine cholinergic neurons in the laterodorsal (LDT) and pedunculopontine (PPT) tegmental nuclei that are implicated in the production of REM sleep (Honda and Semba, 1994); the in vitro demonstration of serotonergic inhibition of mesopontine cholinergic neurons by our laboratory and others (Luebke et al., 1992; Leonard and Llinas, 1994); and the report that microinjection of a serotonergic 5-HT ${ }_{1 \mathrm{~A}}$ agonist into the PPT inhibits REM sleep (Sanford et al., 1994).

We have shown recently that the level of 5-HT release in the cat DRN parallels the time course of presumptively serotonergic neuronal activity: waking (W) > slow wave sleep (SWS) > REM sleep (Portas and McCarley, 1994). These results also implied, we suggested, that the level of 5-HT release measured in the dorsal raphe should index the release level at other axonal projection sites, including the mesopontine cholinergic nuclei. Supporting this assumption was the earlier demonstration that 5-HT levels at 
distant DRN projection sites had the same behavioral state ordering of levels as those in the DRN: W > SWS > REM sleep (in cats: Wilkinson et al., 1991; in rats: Auerbach et al., 1989; Imeri et al., 1994).

The present study was designed to test, in freely moving cats, the hypothesis of serotonergic inhibition of REM sleep. It took advantage of the evidence indicating that axon collaterals of DRN serotonergic neurons inhibit this same DRN population via somatodendritic 5-HT ${ }_{1 \mathrm{~A}}$ receptors (Sprouse and Aghajanian, 1987). Thus, introduction of a selective $5-\mathrm{HT}_{1 \mathrm{~A}}$ receptor agonist in the DRN via microdialysis perfusion should, we predicted, produce strong inhibition of serotonergic neural activity, which would be indicated by a reduction of 5-HT release in the DRN. We further predicted that, if the hypothesis of serotonergic inhibition of REM-promoting neurons were correct, the inhibition of DRN serotonergic activity should disinhibit REM-promoting neurons, producing a increase in REM sleep concomitant with the changes in DRN extracellular 5-HT.

\section{MATERIALS AND METHODS}

Experimental design considerations. The 5- $\mathrm{HT}_{\mathrm{IA}}$ agonist 8-hydroxy-2-(di$n$-propylamino) tetralin (8-OII-DPAT) was selected because of its being the most specific agonist for this receptor (Arvidsson et al., 1981; Gozlan et al., 1983; Middlemiss and Fozard, 1983; Glennon et al., 1988). There were several reasons for choosing the DRN as the localized perfusion site. First, the DRN contains $-40 \%$ of the total 5 -HT neurons present in the cat brainstem (Wiklund et al., 1981). Second, activation of the 5-HT $1 \mathrm{~A}$ receptors widely distributed throughout the mammalian brain, such as would occur with systemic injections, would likely lead to complex and, for the present study, undesirable effects that have been documented in rats: the 5-HT behavioral syndrome with increased motor activity (Higgins et al., 1988), hypothermia (Bill et al., 1991), elevation of plasma adrenocorticotrophic hormone level (Gilbert et al,, 1988), increased sexual activity (Ahlenius et al., 1981), and wakefulness (De St. HilaireKafi et al., 1987; Monti et al., 1990). Lebrand et al. (1994) recently reported that this effect is especially pronounced in the rats whose 5 -HT ${ }_{1 \mathrm{~A}}$ somato-dendritic receptors were eliminated by a selective neurotoxic drug, further suggesting that the wakefulness-inducing effects of 5-HT were mediated by non-DRN sites. Furthermore, Quattrochi et al. (1993) showed a total suppression of REM sleep and ponto-geniculateoccipital (PGO) activity in cats after intravenous administration of a $5-\mathrm{HT}_{1}$ agonist, eltoprazine $\left(2-4 \mathrm{mg} / \mathrm{kg}\right.$ ) (nonspecific for $5-\mathrm{HT}_{1 \mathrm{~A}}$ receptors) whereas total waking was unaltered. Third, the experiments of Adell and coworkers in rat (Adell et al, 1991, 1993) indicated that placing the probe "in the vicinity" of both the DRN and median raphe nuclei and perfusing with low levels $(10 \mu \mathrm{M})$ of 8-OH-DPAT did not affect in vivo 5-HT microdialysate levels. Finally, using low level, microdialysis delivery of 8-OH-DPAT appears important, because administration of high doses of 5-HT via microinjection in or near the DRN in rats elicited heterogeneous behavioral responses, compatible with spread to non-DRN sites: Higgins et al. (1988) reported an increase of "social interaction" and motor activity with DRN injections of $20-200 \mathrm{ng}$ in $0.5 \mu \mathrm{l}$, corresponding to a concentration of $120-1200 \mu \mathrm{M}$. Hutson et al. (1986) observed an increase of food intake after injection of $1 \mu \mathrm{g}$ in $0.5 \mu \mathrm{l}$ in the DRN, corresponding to a concentration of $6 \mathrm{~mm}$. It appears that, in both cases, waking was increased (as with systemic injections). In contrast with these results, Mos et al. (1993) reported, in rats, reduced aggressivity, reduced social interaction and increased inactivity after 8-OH-DPAT ( 1 or 10 $\mu \mathrm{g} / 0.5 \mu \mathrm{l}$, corresponding to a concentration of $6-60 \mathrm{~mm}$ ) was locally injected in the DRN, and Monti and Jantos (1992) reported that injections of $1-4 \mu \mathrm{g}$ in $0.5 \mu \mathrm{l}$ in the DRN (corresponding to a final concentration of 6-24 mM) increased SWS and decreased W, whereas REM was either not affected or was decreased at the lowest dose. The high concentration and rapid application of local injections may lead to activation of non-DRN 5- $\mathrm{HT}_{1 \mathrm{~A}}$ receptors, especially those of nearby mesopontine cholinergic neurons. Because mesopontine cholinergic neurons are inhibited by postsynaptic $5-\mathrm{HT}_{1 \mathrm{~A}}$ receptor activation (Luebke et al., 1992), diffusion or forced ejection of 8-OH-DPAT into this area would act to inhibit the REM sleep-promoting neurons and hence reduce REM sleep percentage.

Animal preparation. Twelve adult cats weighing $\sim 3 \mathrm{~kg}$ were preanes- thetized with a $0.1 \mathrm{ml} / \mathrm{kg}$ dose of a 10:1 mixture of ketamine hydrochloride $(100 \mathrm{mg} / \mathrm{ml})$ and acepromazine maleate $(10 \mathrm{mg} / \mathrm{ml})$. Sodium pentobarbital was administered intravenously $(30 \mathrm{mg} / \mathrm{kg}$ ) to obtain and maintain deep surgical anesthesia. Cats were then stereotaxically implanted with electrodes to record EEG, electrooculogram (EOG), EMG and dorsal lateral geniculate nucleus PGO wave activity. An intracerebral guide cannula (CMA 10/guide, Carnegie Medicine) was implanted $12 \mathrm{~mm}$ above the target to guide the probe to the implantation site, which had Berman atlas (Berman, 1968) coordinates of A 0.6, ML 0, DV - 1. The guide tube and the inserted probe had an angle of angle of $30^{\circ}$ from the vertical to allow the optimal sampling of the DRN while missing the bony tentorium. After surgery the animals were allowed to recover for 2 weeks.

A CMA 10 probe from Carnegie Medicine was used; this had a polycarbonate/polyether copolymer membrane with 20,000 Da molecular weight cutoff, a $500 \mu \mathrm{m}$ diameter, and a $1 \mathrm{~mm}$ tip length. The small size of the probe tip is important because it minimized the diffusion of the drug delivered outside the target zone. The probe was inserted $20-24 \mathrm{hr}$ before starting the experiment to allow for disturbances of the extracellular environment secondary to probe insertion to subside. Before probe insertion, the ependyma of the aqueduct was perforated using a sharp stilette to avoid mechanical damage of the probe en route to the DRN.

Cats were housed individually under conditions of constant light with ad libitum access to food and water and were maintained at constant room temperature $\left(23^{\circ} \mathrm{C}\right)$. Experiments were conducted in a electrically shielded, sound-attenuated chamber that had the same temperature and light conditions as the animals' home cages. The experiment started by perfusing the probe with artificial CSF $(\mathrm{ACSF}=\mathrm{NaCl} 147 \mathrm{mM}, \mathrm{KCl} 4$ $\mathrm{mm}, \mathrm{CaCl}_{2} 2.3 \mathrm{~mm}, \mathrm{pH} 7.2$ ) at a flow rate of $1.5 \mu \mathrm{l} / \mathrm{min}$ using a microdialysis pump (CMA 100, Carnegie Medicine). To record behavioral states the animals were connected to a polygraph (Grass model 6A); dialysis perfusate was collected via a dual channel microdialysis swivel (Instech Laboratories, PA) incorporated into an electrical swivel (Airflyte Electronics, Bayonne, NJ). Each sample was taken over a 5 min period (at 1.5 $\mu \mathrm{l} / \mathrm{min}=7.5 \mu \mathrm{l} / \mathrm{sample})$, and the time delay attributable to the dead volume of the system (Hluid contained in the output perfusate tubing, the swivel and the probe) was taken into account in correlating neurochemical readings with the EEG recording of behavioral state.

5-HT analysis. Samples were injected in a microbore HPLC system (Bioanalytical Systems, West Lafayette, IN) $(10 \mu \mathrm{l}$ loop, Rheodyne injector model 9125-087A) coupled to an electrochemical detector (LC-44, Bioanalytical Systems). Separation was achieved using a SepStik microbore column ODS ( $3 \mu \mathrm{m}$ particle size) and a mobile phase consisting of ethylcncdiaminetctraacctic acid $0.185 \mathrm{gm} / 1$, sodium octyl sulfate 0.15 $\mathrm{gm} / \mathrm{l}$, sodium phosphate $0.1 \mathrm{M}$, acetonitrile $12 \%, \mathrm{pH} \sim 5$. The detection limit for $5-\mathrm{HT}$ in the dialysate was $\sim 0.5 \mathrm{fmol} / \mathrm{sample}$.

Chromatographic data were recorded and concentrations determined by a Shimadzu (CR3A, Kyoto, Japan) integrator using an external standard calibration curve. 5-HT in dialysis solutions was identified by comparing retention times of 5-HT standards (5-HT, Sigma, St. Louis, MO) to the retention times of sample peaks identified as 5-HT (matched within $0.04 \mathrm{~min}$ ). As described previously (Portas and McCarley, 1994), we also confirmed the identical retention time of the putative sample 5-HT peak and that of a known amount of 5-HT added to the dialysate sample. With placements of the probe in the aqueduct, no 5-HT signal was detected.

Statistical procedures. The main hypothesis was that 8-OH-DPAT perfusion would produce an augmentation in REM sleep, compared with control ACSF perfusion, and that this reduction in REM sleep would be accompanied by a reduction in DRN 5-HT release. This hypothesis was evaluated by $t$ tests performed on $\log _{10}$-transformed data (to stabilize variance), and the significance levels of tests of this hypothesis, and other, nonpredicted changes in state and 5-HT release were indicated by conservative two-tail probability measures.

Experimental protocol. Animals were connected to a polygraph and ACSF perfusion started at least $1 \mathrm{hr}$ before sampling began. Multiple samples were obtained from the DRN across behavioral states during the period 12 noon to 10 P.M. The $2 \mathrm{hr}$ between 6 P.M. and 8 P.M. was used as a control time window for determining baseline W, SWS, and REM values. This period of time offered conditions similar to the ones obtained during the 8-OH-DPAT perfusion, that is, same experimental day, same phase of circadian rhythm, and the presence of the microdialysis probe in DRN. At 8 P.M. the ACSF perfusate was replaced by one containing ACSF +8 -OH-DPAT, $10 \mu \mathrm{m}$. The drug was continuously perfused for 2 hr (approximately 8 P.M. to 10 P.M., with perfusion always beginning in waking). For comparison of 5-HT levels during the same state (waking), at least two samples/animal were obtained in the $2 \mathrm{hr}$ of the baseline 
control period (before 8-OH-DPAT) and also during the $2 \mathrm{hr}$ of $8-\mathrm{OH}$ DPAT perfusion. At 10 P.M. perfusion with ACSF alone was resumed and the animal was recorded for 1 more $\mathrm{hr}$ before ending the experiment.

In vitro dialysis test procedure. In vitro perfusion was used to test the bidirectional dialyzing properties of the probe for both $5-\mathrm{HT}$ and $8-\mathrm{OH}$ DPAT. First, the recovery of 5-HT by each probe was calculated. To do so each probe was immersed in a liquid containing a known amount of 5-HT and the ACSF perfusion started. The flow rate used was identical in both in vivo and in vitro conditions. Under these circumstances the average relative recovery for $5-\mathrm{HT}$ was $12 \%$ (for an extensive review of microdialysis technique, see Robinson and Justice, 1991). Secondly, the diffusion of 8-OH-DPAT through the probe was evaluated. The drug was introduced at a concentration of $10 \mu \mathrm{M}$ in ACSF. Diffusion from the probe into the surrounding $1 \mathrm{ml}$ volume of ACSF was then examined by assaying 8-OH-DPAT using HPLC electrochemical detection analysis.

Histology. For histological verification of the probe placement, animals were killed under pentobarbital anesthesia. The brains were perfused via the ascending aorta with $300 \mathrm{ml}$ of ice-cold saline followed by $2 \%$ formaldehyde in $0.1 \mathrm{M}$ phosphate buffer. The brains were then blocked, placed overnight in fixative, and transferred to $15 \%$ sucrose, $0.1 \mathrm{M}$ phosphate buffer until equilibration. The brainstem was isolated, and sections were cut at $40 \mu \mathrm{m}$ thickness on a freezing microtome. One series of sections (one-in-four) was stained with cresyl violet for histology. In two of the five cats with 8-OH-DPAT perfusion in the DRN, one-in-four series of sections were processed for 5-HT immunohistochemistry (polyclonal 5-HT antibody raised in rat, Eugene Tech. International, Ramsey, $\mathrm{NJ})$ to verify the placement of the probe among 5-HT-containing neurons.

Of the 12 animals prepared, 5 , all with probes histologically localized to the DRN, were used to measure the effects of 8-OH-DPAT perfusion in this region (all 5 had behavioral measures, 4 had simultaneous determination of extracellular 5-HT); 3 animals had probes localized to the aqueduct and were used as controls; and 1 animal had the probe localized in the tegmentum but outside the raphe. The three remaining animals had DRN-localized probes: two were used for low calcium perfusate experiments and one was used for tetrodotoxin (TTX) perfusion.

\section{RESULTS}

All animals had histology for localization of the probe tip, with perfusion performed 2-6 d after each experiment. In each of the five cases described here as DRN perfusion, the probe tip was found to be located within the DRN and immunohistochemistry showed this to be within a field of serotonergic neurons (see Fig. 1). Chromatograms showing 5-HT level alterations during each polygraphically defined behavioral state and during 8-OH-DPAT perfusion are illustrated in Figure 2. This figure also shows that the retention times of the 5-HT peaks were nearly identical in all chromatograms, indicating detection of the same compound. Note that there was a clear ordering of amplitudes of the 5-HT peak during the spontaneously occurring behavioral states: $\mathrm{W}>$ SWS $>$ REM. This figure also shows that, compared with spontaneous waking, perfusion with 8-OH-DPAT produced a marked reduction in levels of 5-HT during the same polygraphically defined state.

\section{Overview of experimental paradigm and effects of 8-OH-DPAT perfusion}

The time course of DRN 5-HT levels and behavioral state before and during addition of $10 \mu \mathrm{M} 8-\mathrm{OH}$-DPAT to the microdialysis perfusate are illustrated for a typical experiment in Figure 3. Examination of this figure shows that, during the $2.75 \mathrm{hr}$ before addition of 8-OH-DPAT, the spontaneously occurring behavioral state percentages were: $\mathrm{REM}$ sleep $=6 \%$, SWS $=16 \%$, and $\mathrm{W}=$ $78 \%$. Note also that these spontaneous states showed a clear correspondence of relatively high levels of 5-HT ( $>2 \mathrm{fmol} / 7.5 \mu \mathrm{l}$ dialysate sample) with the W state, whereas SWS and REM had lower levels. After addition of 8-OH-DPAT to the perfusate, there was a large change in both the percentages of the behavioral states and also in the level of 5-HT. Throughout the perfusion, the
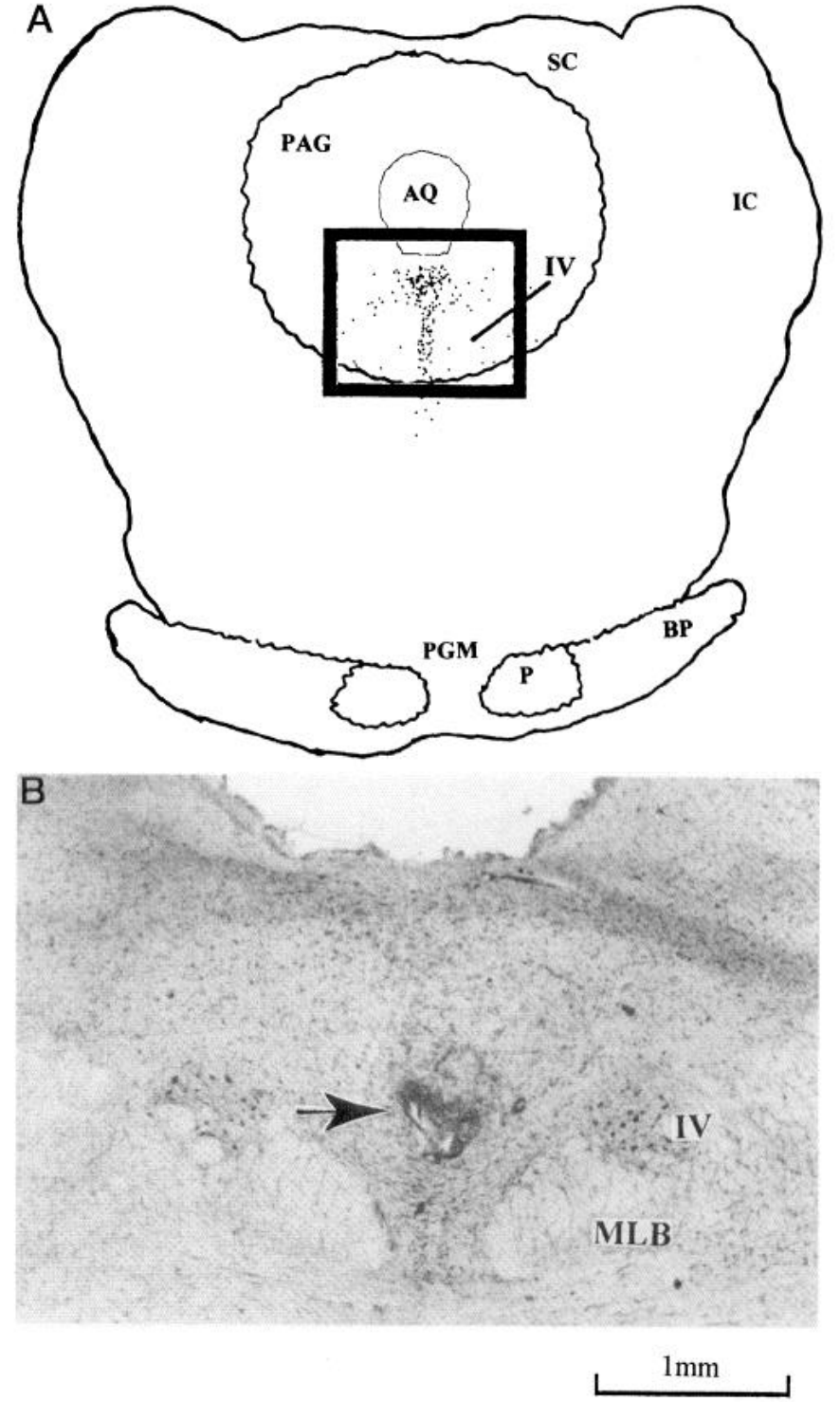

Figure 1. A, Schematic coronal section of the cat brainstem $(\sim$ A 0.5$)$ illustrating location of probe tip (inset, $B$ ). In $A$, dots represent serotonergic cells visualized with 5-HT immunohistochemistry at this location (illustration adapted from Shiromani et al., 1992). B, Photomicrograph showing the location of the probe tip within the DRN (arrow), corresponding to the inset of $A$. (The probe entered the brainstem at an angle of $30^{\circ}$ from the vertical and, thus, on this single coronal section, the more posterior track of the probe is not visible.) Scale bar, $1 \mathrm{~mm}$. Abbreviations: $A Q$, aqueduct; $P A G$, periaqueductal gray; $I V$, nucleus of the fourth cranial nerve; $M L B$, median longitudinal bundle; $S C$, superior colliculus; $I C$, inferior colliculus; $P$, pyramidal tract; $B P$, brachium pontis; $P G M$, pontine gray, median division.

level of 5 -HT remained $<2 \mathrm{fmol} / \mathrm{sample}$, while the REM sleep percentage increased to $19 \%$, the SWS percentage increased to $39 \%$, and the W percentage decreased to $42 \%$.

\section{Quantitative and statistical evaluation of the effects of DRN perfusion of 8-OH-DPAT}

DRN 8-OH-DPAT perfusion reduced 5-HT levels

The extracellular concentration of 5-HT in DRN was assessed in four cats. In each animal multiple microdialysis samples (minimum two, maximum four for each behavioral state) were collected during the control window (between 6 P.M. and 8 P.M.) and 


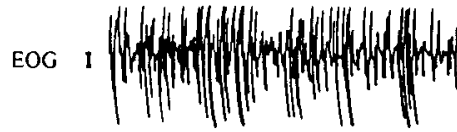

EMG

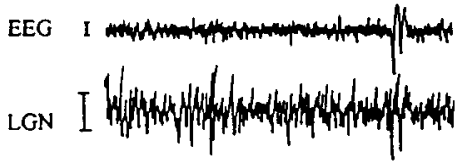

LGN

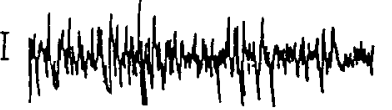

$50 \mu \mathrm{V}$

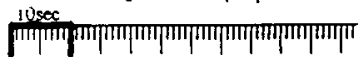

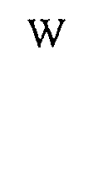
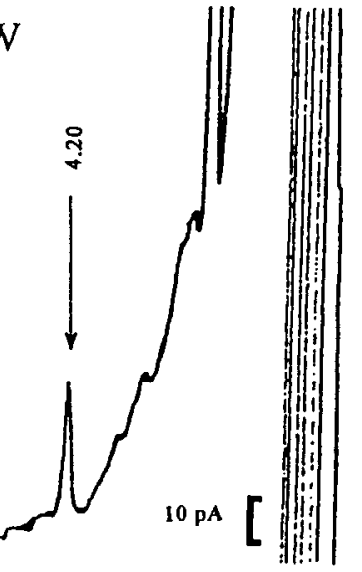

\section{SWS}
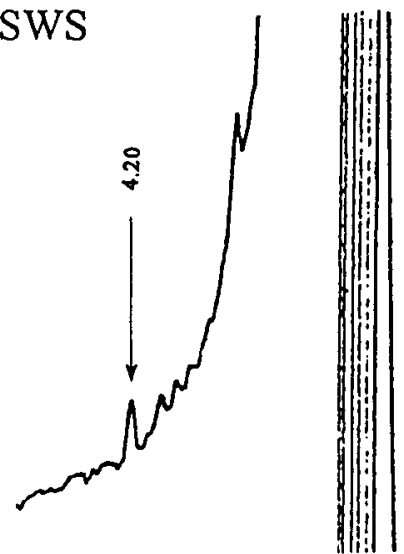
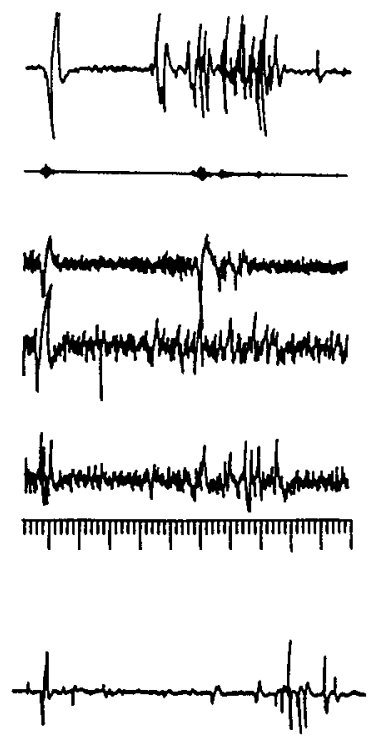

REM
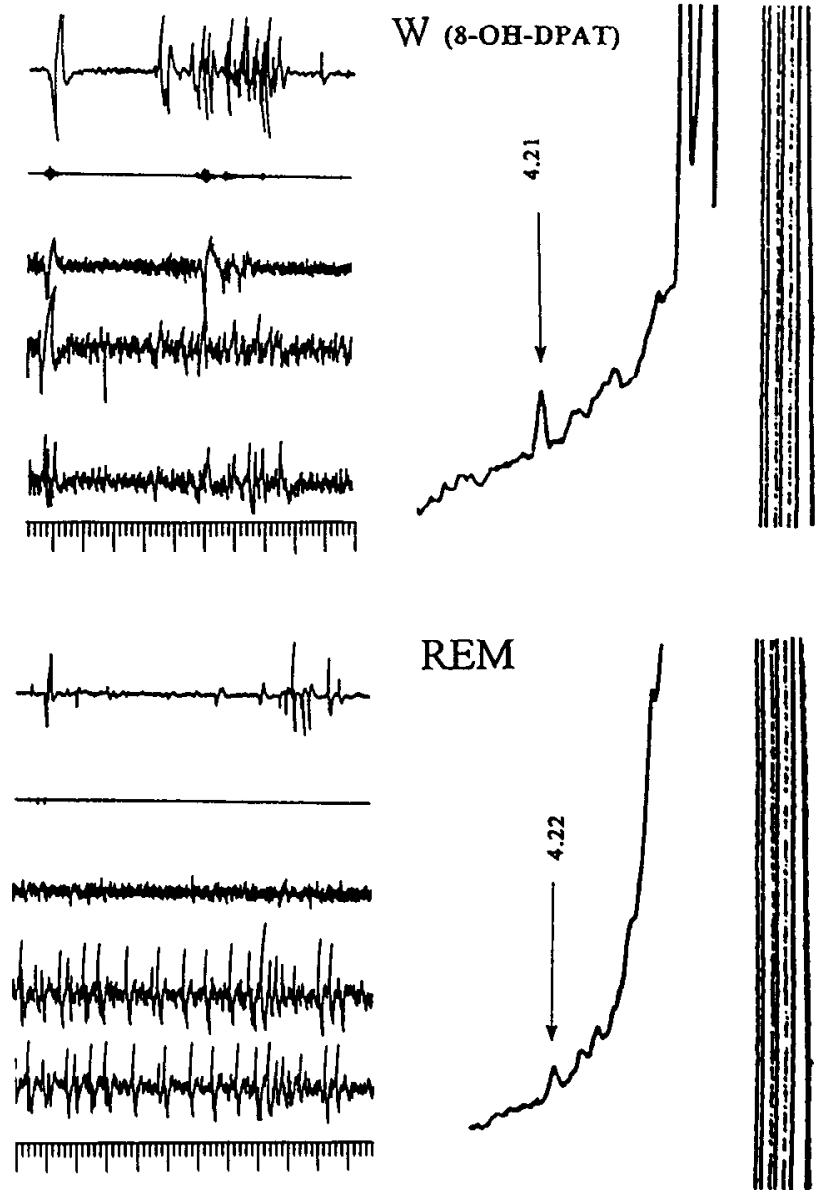

Figure 2. Polygraphically defined behavioral state and corresponding DRN 5-HT signal amplitude. The left side of each panel shows the polygraphic recordings during each spontaneously occurring state and also (top right panel) waking during 8-OH-DPAT perfusion (voltage calibration, $50 \mu \mathrm{A}$; time calibration, $10 \mathrm{sec}$ ). The right side of each panel displays the corresponding chromatograms, each showing 5-HT levels (arrows) in dialysate collected during the specific behavioral state. Note the marked reduction in amplitude of the 5-H'I peak during 8-OH-DPAT perfusion compared with baseline waking, and the ordering of amplitudes $W>S W S>R E M$ during spontaneously occurring behavioral states (sensitivity calibration in top left panel, 10 $\mathrm{pA}$ ). Note also that the retention time (in min) across chromatograms remains quite constant. Abbreviations: $W$, waking; $S W S$, slow wave sleep; $R E M$, rapid eye movement sleep; $E E G$ electroencephalogram; $E O G$, electrooculogram; $E M G$, electromyogram; $L G N$, lateral geniculate nucleus; note PGO spikes.

during perfusion of 8-OH-DPAT (between 8 P.M. and 10 P.M.). 8-OH-DPAT $(10 \mu \mathrm{m})$ consistently decreased 5 -HT release to $\sim 50 \%$ of baseline levels, from $3.9 \pm 0.3 \mathrm{fmol} / \mathrm{sample}$ in baseline waking (mean \pm SEM, $n=11$ samples) to $2.0 \pm 0.28 \mathrm{fmol} / \mathrm{sample}$ in the same state during 8-OH-DPAT perfusion (mean \pm SEM, $n=10$ samples) as illustrated in Figure $4(p<0.01$, Student's $t$ test, $t=4.38$, $19 \mathrm{df}$, two-tailed). These results were also statistically significant when based on paired comparisons between the four animals; in this case baseline waking values of $4.06 \pm 0.41$ $\mathrm{fmol} / \mathrm{sample}$ fell to $2.15 \pm 0.44 \mathrm{fmol} / \mathrm{sample}$ in the same state during 8-OH DPAT perfusion ( $p=0.004$, paired $t$ test, $t=8.42$, $3 \mathrm{df}$, two-tailed).

\section{DRN 8-OH-DPAT perfusion increased REM sleep}

As illustrated in Figure 5, perfusion of 8-OH-DPAT in the DRN produced a strong effect on behavioral state distribution. As predicted, the experimental condition, compared with the control condition, showed a statistically significant threefold increase of REM sleep, from $10.6 \pm 2.34 \%$ (control condition, mean \pm SEM) to $30.6 \pm 7.16 \%$ (during $8-\mathrm{OH}-\mathrm{DPAT}$ perfusion) of total recorded time ( $p<0.05$, paired $t$ test, $t=3.18,4 \mathrm{df}$, two-tailed). REM sleep onset was usually $\sim 10$ min after drug perfusion began, when 8-OH-DPAT concentration was still very low in the DRN. Although $W$ time fell from $54.3 \pm 11.78 \%$ (control condition) to $33.8 \pm 12 \%$ (during 8-OH-DPAT perfusion), this was not statistically significant ( $p=0.274$, paired $t$ test, $t=1.27,4 \mathrm{df}$, twotailed, five animals). As shown in Figure 5, SWS percentage was virtually unchanged ( $p=0.702, t=0.41,4 \mathrm{df}$, two-tailed, 5 animals).

\section{8-OH-DPAT perfusion and fine-grain analyses of behavioral state}

Because 5-HT has long been suspected of having a suppressive effect on PGO wave activity over and above that postulated for the REM state as a whole (see review in Steriade and McCarley, 1990), the number of PGO waves occurring in 1 min sample periods (randomly selected, manually counted) of natural REM was compared with the number of PGO waves occurring in $1 \mathrm{~min}$ sample periods (randomly selected) of REM sleep during 8-OHDPAT perfusion into the DRN ( $n=5$ samples from two animals). The apparent increase of $\mathrm{PGO}$ waves was proportionate to the increase in the entire REM sleep state duration. Nor was there any difference in the number of PGO spikes in the $2 \mathrm{~min}$ before REM sleep onset (transition period) before and during $8-\mathrm{OH}$ - 


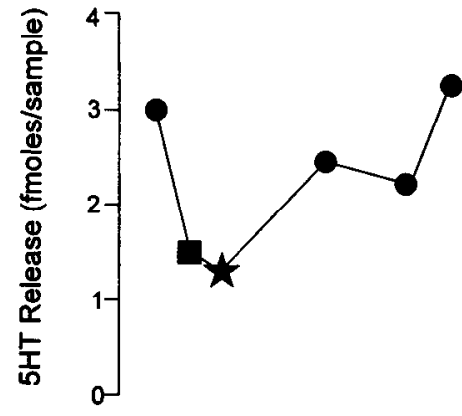

Figure 3. Time course of 5-HT levels (top portion of figure) and behavioral state (bottom portion of figure) during control DRN ACSF perfusion (intermpted horizontal line) and during DRN 8-OH-DPAT perfusion (solid horizontal line) in a typical experiment. Note that, before perfusion, waking DRN 5-HT levels (circles) are higher than those in SWS (squares) and REM sleep (stars). Each 5-HT value is expressed as fmol/7.5 $\mu \mathrm{l}$ sample and was obtained during an uninterrupted $5 \mathrm{~min}$ sequence of the behavioral state. After onset of $10 \mu \mathrm{M}$ 8-OH-DPAT perfusion (arrow), the 5-HT level dropped quickly to levels as low as those normally present in SWS or REM. Behaviorally, 8-OH-DPAT administration markedly increased REM sleep from 6 to $19 \%$ (black bars in the hypnogram).

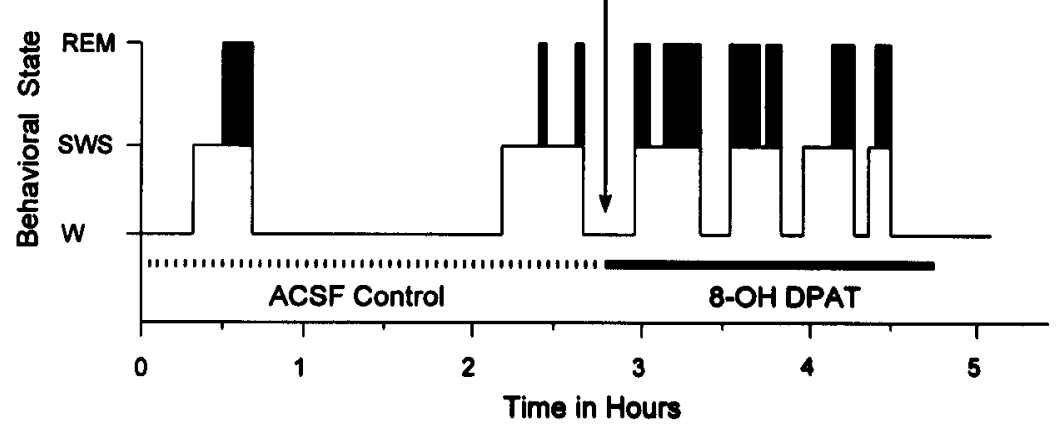

DPAT perfusion (data not shown). With respect to motor activity, it was our impression that activity was less during waking after 8-OH-DPAT than spontaneous waking (Fig. 2 has less movement artifact in waking after 8-OH-DPAT). However, because this study was focused on sleep, we did not rigorously quantify motor activity. We attempted to evaluate for differences in DRN 5-IIT levels during SWS1 and SWS2; however, we were unable to obtain sufficient 5 min continuous samples of SWS1 and SWS2 and hence did not include SWS1 and SWS2 in the analyses of this study.

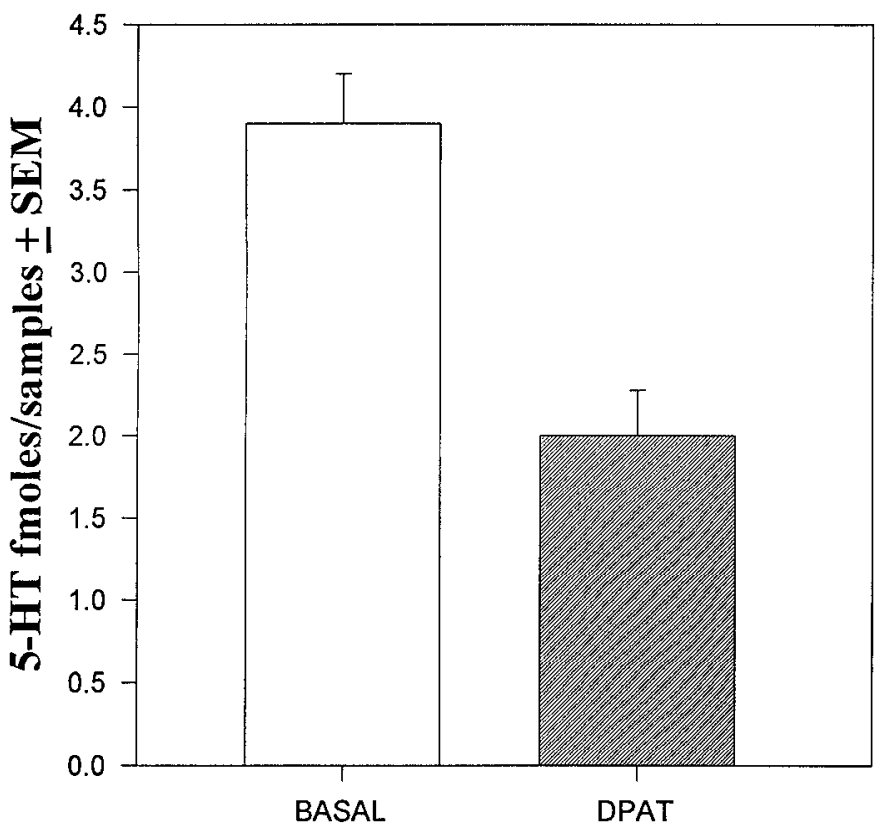

Figure 4. Reduction of mean levels of DRN extracellular 5-HT in W during perfusion with $10 \mu \mathrm{M}$ 8-OH-DPAT in ACSF ( $n=11$ samples) compared with that in $\mathrm{W}$ during perfusion with $\mathrm{ACSF}$ alone $(n=10$ samples; $p<0.01$, Student's $t$ test). Error bars are SEM.

\section{Effects of 8-OH-DPAT perfusion at non-DRN sites Aqueductal 8-OH-DPAT perfusion did not increase REM}

To investigate the specificity of the behavioral effects of DRN perfusion, in three animals 8-OH-DPAT was perfused into the aqueduct. As illustrated in Figure 6, the effects were quite different than with DRN perfusion. First, REM was not increased but was nonsignificantly decreased ( $p=0.69$, paired $t$ test, $t=0.54,2$ df, 3 animals). With aqueductal perfusion there was a trend level increase in wakefulness, from control values of $56.3 \pm 5.6 \%$ to 84 $\pm 8.09 \%$ ( $p=0.08$, paired $t$ test, $t=3.36$, two tailed, $2 \mathrm{df}, 3$ animals). Aqueductal perfusion also produced a trend level decrease in SWS from control values of $36.6 \pm 3.93 \%$ to $14.7 \pm$ $7.69 \%$ ( $p=0.10$, paired $t$ test, $t=2.85,2 \mathrm{df}, 3$ animals).

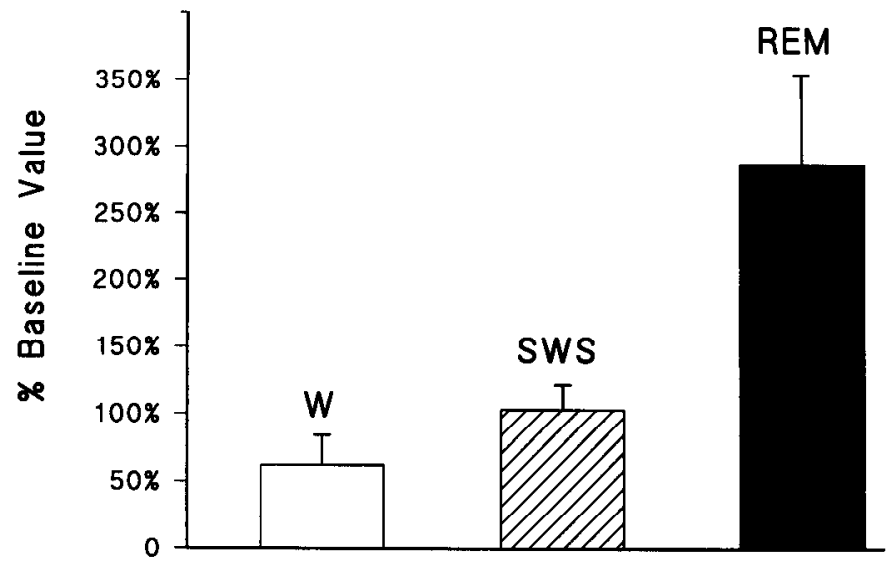

Figure 5. Effect on behavioral state of DRN perfusion with 8-OH-DPAT $(10 \mu \mathrm{M})$, expressed as percentage change versus baseline values $(n=5$ animals). Note the large and statistically significant increase in $R E M$ sleep; $S W S$ was virtually unchanged, and $W$ was reduced, but not statistically significantly so (see text). Error bars are SEM. 


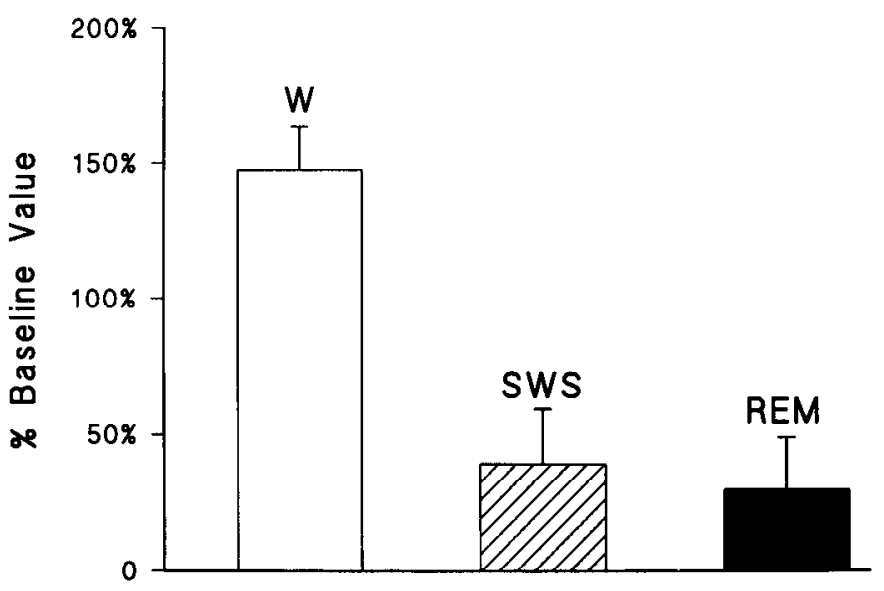

Figure 6. Effect on behavioral state of intra-aqueductal perfusion with 8-OH-DPAT $(10 \mu \mathrm{M})$, expressed as percentage change versus baseline values ( $n=3$ animals). In contrast to DRN perfusion (Fig. 5), there is no $R E M$ increase, and there is a trend for an increase in $W$ and a reduction in SWS. Error bars are SEM.

\section{Perfusion of 8-OH-DPAT in the tegmentum ventral to DRN} did not affect behavioral state

In one case, 8-OH-DPAT was perfused $4 \mathrm{~mm}$ ventral to DRN. Under these conditions no change in behavioral state were observed (data not shown).

\section{Estimation of 8-OH-DPAT delivery: an \\ "in vitro" approximation}

To obtain a rough order of magnitude estimate of the quantity of 8-OH-DPAT perfused through the probe over the $2 \mathrm{hr}$ period, we tested in vitro the diffusion of 8-OH-DPAT (10 $\mu \mathrm{M}$ concentration) into a static $1 \mathrm{ml}$ of $\Lambda \mathrm{CSF}$ surrounding the probe. The concentration of the drug in the surrounding medium rose over the $2 \mathrm{hr}$ to a maximal value of $1.7 \mu \mathrm{M}(\sim 500 \mathrm{ng} / \mathrm{ml}$ 8-OH-DPAT). Because $1 \mathrm{ml}$ is probably an overgenerous estimate of the true (but unknown) extracellular compartment volume, the figure of $500 \mathrm{ng}$ of 8-OH-DPAT delivery is likely an overestimate (Fig. 7). Similarly, we consider the extracellular concentration only an order of magnitude estimate. (We note that in vivo diffusion of the drug will be dependent on several factors, including the multicompartmental gradient effect, that are currently unknown.) The in vitro quantification of 8-OH-DPAT diffusion did verify the bidirectional dialyzing property of the microdialysis probes (essential for the experiment) and appears to offer an order of magnitude estimate of the amount of drug delivered in the DRN. We note that the amount obtained is of the same order of magnitude as the physiologically specific 8 -OH-DPAT concentrations generally used in in vitro electrophysiological studies of dorsal raphe neurons in the rat (Hodgkiss et al., 1992, $10 \mu \mathrm{M}$; Penington et al., 1993, $0.1 \mu \mathrm{M}$; Williams et al., 1988, $1 \mathrm{nM}$ to $1 \mu \mathrm{M}$ ).

\section{Calcium- and action potential activity-dependent 5-HT release in the DRN}

In previous studies neurotransmitter release estimated by in vivo microdialysis has been reported to be dependent on the presence of $\mathrm{Ca}^{2+}$ ions in the ACSF (Carboni and Di Chiara, 1989). We therefore examined the effects of $0 \mathrm{mM} \mathrm{Ca}^{2+}$ in the ACSF on 5-HT release within the DRN. This procedure reduced 5-HT release to $\sim 20 \%$ of baseline output. 5-HT levels returned to control values $\sim 30 \mathrm{~min}$ after the replacement of $\mathrm{Ca}^{2+}$-free ACSF with normal ACSF ( $n=2$ animals, Fig. 8). During this experiment

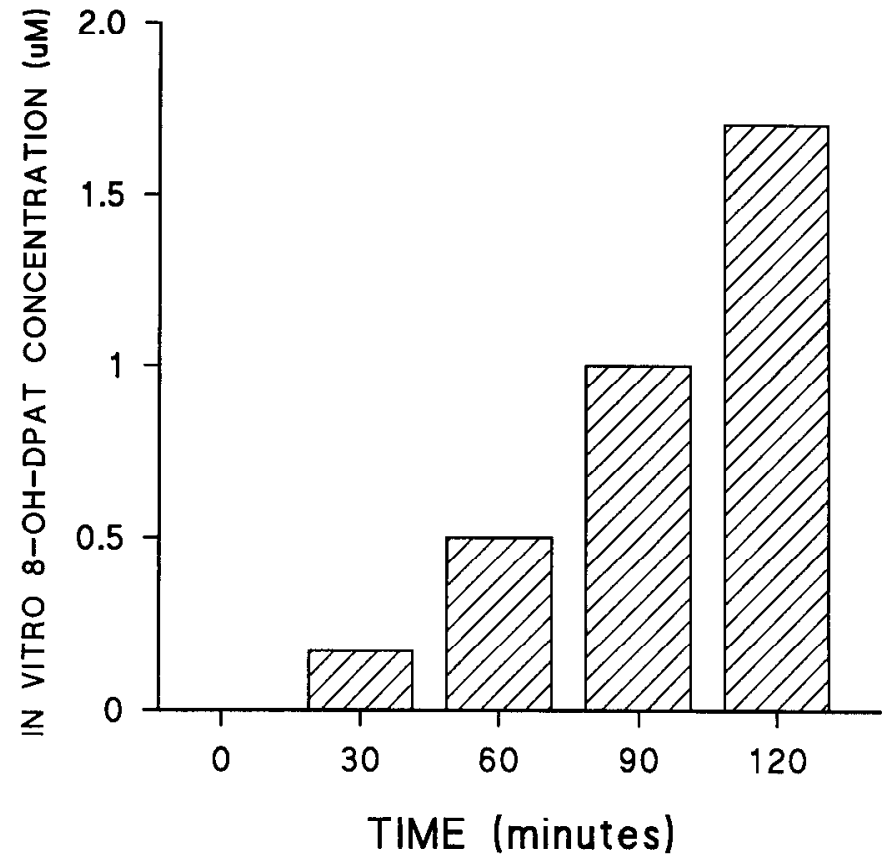

Figure 7. In vitro measurements of 8-OH-DPAT concentration uutside the microdialysis probe as a function of perfusion duration (perfusate concentration of $10 \mu \mathrm{M}$, external ACSF volume of $1 \mathrm{ml}$ ). 8-OH-DPAT concentration was $0.17 \mu \mathrm{M}$ after $30 \mathrm{~min}, 0.5 \mu \mathrm{M}$ after $60 \mathrm{~min}, 1 \mu \mathrm{M}$ after $90 \mathrm{~min}$, and a maximal concentration of $1.7 \mu \mathrm{M}$ was achieved after $120 \mathrm{~min}$.

no polygraphic recording was performed. We also investigated the effect of TTX, a highly specific $\mathrm{Na}^{+}$channel blocker, on 5-HT release. In one animal, perfusion of TTX $(0.5 \mu \mathrm{M})$ reduced 5-HT release to $40 \%$ of basal levels over a period of $80 \mathrm{~min}$. 5-HT release was still reduced even after a $3 \mathrm{hr}$ washout period, corresponding to the observed long duration of TTX activity when administered in vivo (Kao, 1966).

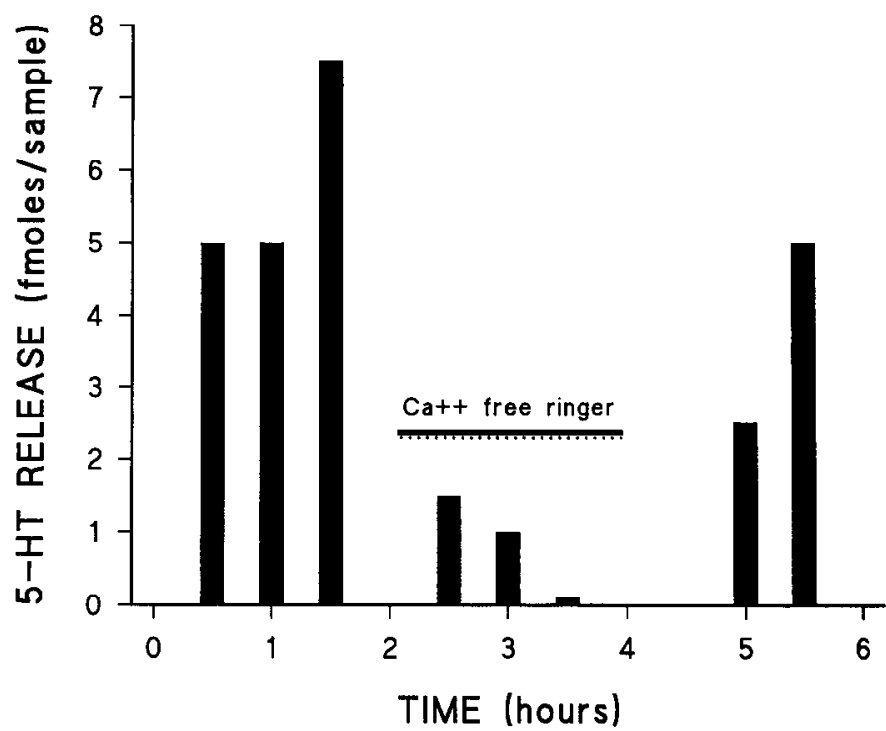

Figure 8. Effect on DRN extracellular 5-HT of $\mathrm{Ca}^{2+}$ free ACSF perfusion. 5-HT levels are expressed as fmol/7.5 $\mu \mathrm{l}$ sample. Note the decrease of 5-HT to $\sim 20 \%$ of baseline values. 5 -HT levels returned to control values $\sim 30 \mathrm{~min}$ after the replacement of $\mathrm{Ca}^{2+}$-free ACSF with normal $\operatorname{ACSF}(n=2$ animals). 


\section{DISCUSSION}

The data of the present study support the hypothesis that DRN serotonergic activity suppresses REM sleep (McCarley and Hobson, 1975; McGinty and Harper, 1976; McCarley and Massaquoi, 1992). Inhibition of DRN serotonergic neural activity via microdialysis-perfused 8-OH-DPAT, a selective 5-HT ${ }_{1 \mathrm{~A}}$ agonist, produced a threefold increase in the percentage of REM sleep. This behavioral increase in REM sleep was paralleled by a concomitant and consistent decrease in simultaneously measured extracellular DRN 5-HT levels in the DRN, which decreased to $\sim 50 \%$ of baseline levels, from $\sim 4 \mathrm{fmol} / \mathrm{sample}$ in baseline waking to $\sim 2 \mathrm{fmol} / \mathrm{sample}$ in the same state during 8-OH-DPAT perfusion.

We hypothesize that this DRN 8-OH-DPAT-induced increase in REM sleep was mediated by a decrease in discharge levels of serotonergic DRN neurons and a resulting decrease in levels of 5-HT at DRN projections to mesopontine cholinergic neurons. Before discussing the role of mesopontine cholinergic neurons, we first cite three lines of evidence supporting a three-way parallelism among: DRN (presumptively) serotonergic neuronal discharge, and levels of 5-HT, both at distant projection sites of DRN and also within the DRN. (1) During naturally occurring sleep-wake cycles changes in discharge rate of DRN serotonergic $(W>$ SWS $>$ REM sleep) parallel changes in the level of DRN 5-HT (Portas and McCarley, 1994, and confirmed by the present study). (2) During naturally occurring sleep-wake cycles, 5-HT levels at distant DRN projection sites in cats (Wilkinson et al., 1991) and rats (Awerbach et al., 1989, Imeri et al., 1994) have the same $W>$ SWS $>$ REM sleep ordering as the discharge rates of DRN serotonergic neurons and of DRN 5-HT levels. (3) 8-OH-DPAT, a specific $5-\mathrm{HT}_{1 \mathrm{~A}}$ agonist known to inhibit DRN serotonergic neuronal discharge, when delivered to the DRN, reduces 5-HT release both at distant DRN projection sites (Bonvento et al., 1992, in the rat), and also within the DRN (the present study). What might mediate this three-way parallelism? At DRN distant projection sites, action potential-induced axonal release most likely accounts for the parallels in changes of discharge rate and 5-HT levels. A similar axonal release mechanism could account for the parallelism of discharge rates and 5-HT levels in the DRN, because there are recurrent axonal collaterals (Sprouse and Aghajanian, 1987) and recent in vitro experiments (O'Connor and Kruk, 1992) have demonstrated that application of 8-OH-DPAT to brain slices containing the DRN produced a concentrationdependent reduction in stimulation-induced relcase of DRN 5-HT. However, there are data in the rat indicating the possibility of nonaxonal (somatodendritic) 5-HT release (Adell et al., 1993). If somatodendritic 5-HT release were to occur concomitantly with axonal action potentials, as might occur with either backpropagation of axonal action potentials or with forward propagation of dendritic spikes (Stuart and Sakmann, 1994), this also could account for the observed coupling.

With respect to the DRN projections likely to be involved in the REM sleep effects, there is now considerable evidence supporting the importance of mesopontine cholinergic neurons in REM generation. This includes anatomical evidence of projection to the pontine reticular formation (PRF, Mitani et al., 1988), a zone containing effector neurons for many of the phenomena of REM sleep and where injections of cholinergic agonists produce a state mimicking REM sleep (see review in Steriade and McCarley, 1990). Furthermore, there is evidence in cats that ACh release in PRF derives from mesopontine cholinergic neurons (Lydic and
Baghdoyan, 1993), and recently it has been shown in cats that ACh release is enhanced in PRF during naturally occurring REM sleep (Leonard and Lydic, 1995), as well as in more dorsal and rostral pontine regions (Kodama et al., 1990).

Other data support our hypothesis of DRN serotonergic inhibition of mesopontine cholinergic neurons. Anatomical data indicate DRN serotonergic projections to mesopontine cholinergic neurons (Honda and Semba, 1994), and in vitro physiological experiments demonstrate that 5-HT inhibits identified mesopontine cholinergic neurons in the rat (Luebke et al., 1992; Leonard and Llinas, 1994). Moreover, 8-OH-DPAT, but not a 5-HT agonist without specificity for the $5-\mathrm{HT}_{1 \mathrm{~A}}$ receptor subtype, suppresses REM and $\mathrm{PGO}$ wave occurrence in in vivo microinjections into the PPT in cats (Sanford et al., 1994). Thus, it is plausible that suppression of DRN activity might disinhibit mesopontine cholinergic neurons and thereby increase REM sleep. However, only in vivo studies of REM sleep effects are capable of addressing the question of whether the demonstrated serotonergic inhibition is sufficiently strong so that its reduction would significantly affect REM sleep. The present data suggest that DRN activity is indeed important in REM suppression, and, together with anatomical and both in vitro and in vivo physiological data, are consistent with the mediation of this REM suppression via DRN serotonergic projections to mesopontine cholinergic neurons. Historically, the question of DRN inhibition of REM sleep has been an important but unresolved conundrum for some 20 years: the hypothesis of monoaminergic disinhibition leading to REM sleep was proposed in McCarley and Hobson's theoretical paper (1975) and in McGinty and Harper's empirical paper (1976).

From a methodological point of view, the present data suggest the utility and practicality of using microdialysis to apply pharmacological agents to nuclei putatively involved in REM sleep regulation, and thereby to offer empirical tests of hypothesized mechanisms. The contrast of behavioral effects of 8-OH-DPAT when administered within the DRN and when administered at other brain sites and systemically also seems worthy of emphasis. The effects of aqueductal administration are compatible with the results of previous systemic administration studies in cats (Adrien and Hamon, 1989) and rats (De St. Hilaire-Kafi et al., 1987; Monti et al., 1990). A potential problem with large probes placed "in the vicinity" of the raphe (Adell and Artigas, 1991: in rats, dialyzing membrane length $=3.5 \mathrm{~mm}$ ) is that the zone sampled almost certainly will include areas that are very heterogeneous with respect to intrinsic and afferenting neurotransmitters; these zones include the LDT tegmental nucleus (Luebke et al., 1992; Semba, 1993; Honda and Semba, 1994), the locus coeruleus (Pickel et al., 1977), and the reticular formation (Semba, 1993), zoncs in which 5-HT would produce quite different results than in DRN. Voltametric measurements of 5-hydroxyindoles during the sleep-wake cycle (Houdouin et al., 1991) appear to have a limited specificity because the primary signal comes from 5-HIAA, the level of which is not closely correlated with that of $5-\mathrm{HT}$, as shown by Auerbach et al. (1989) and Crespi et al. (1990) and by our own data (Portas and McCarley, 1994).

We note that the present study primarily examined REM sleep effects and was not designed to measure motor behavior quantitatively; we thus could not test a hypothesized link of motor behavior and serotonergic activity (Jacobs and Fornal, 1993). Nor were there sufficient sample periods of pure SWS1 or SWS2 (light and deep SWS, respectively) to allow a quantitative measure of 5-HT levels, and we consequently did not include these variables in the present study. The concentrations of 8-OH-DPAT in the 
present study are much lower than those shown to induce hypothermia (Higgins et al., 1988; Bill et al., 1991), which can modulate behavioral state (McGinty and Szymusiak, 1990). Because norepinephrine, like 5-HT, has been shown to inhibit mesopontine cholinergic neurons in vitro (Williams and Reiner, 1993) and norepinephrinergic locus coeruleus neurons show the same REM sleep-related discharge rate decrease (Hobson et al., 1975) as DRN neurons, the present data suggest that analogous microdialysis experiments might be useful in locus coeruleus, using an $\alpha_{2}$ receptor agonist.

We conclude that the REM enhancement after 8-OH-DPAT microdialysis represents the behavioral response dependent on a reduction in serotonergic neuronal discharge activity within the DRN and on a concomitant reduction in DRN axonal 5-HT release. Given the data indicating 5-HT inhibition of mcsopontinc cholinergic neurons and the their role in REM sleep (see above), we think it is likely that the increase in REM sleep is mediated by a disinhibition of cholinergic REM-promoting mesopontine neurons. We note that determination of a reduction in extracellular 5-HT in the mesopontine cholinergic zone in the course of our experimental protocol of control and 8-OH-DPAT infusion would offer somewhat more direct evidence, although there is little reason to suspect that there would not be a REM sleep-related reduction in extracellular 5-HT in the mesopontine zone, given its presence in other DRN projection targets (and we also note the considerable technical difficulty of simultaneous placement of two microdialysis probes in the DRN and in the very nearly adjacent mesopontine region).

Overall, these experimental data support the postulate (McCarley and Hobson, 1975; McCarley and Massaquoi, 1992) that the naturally occurring decrease in discharge rate of DRN monoaminergic neurons that occurs during spontaneous SWS and before REM sleep may act to disinhibit the mesopontine cholinergic neurons shown to be REM-active (Steriade et al., 1990) and thus promote the occurrence of REM sleep. As discussed in our theoretical paper (McCarley and Massaquoi, 1992), this raises the question of what mechanisms lead to a decrease in discharge rate of DRN neurons. One possibility is increased activation of DRN GABAergic inhibitory interneurons (Nishikawa and Scatton, 1985; Nitz and Siegel, 1993), although the mechanisms for this activation remain unknown. Another, and nonexclusive possibility, is that sustained activation of DRN somato-dendritic 5-HT receptors, as occurs with high DRN discharge levels during wakefulness, may produce a long-lasting inhibition through second messenger mechanisms (McCarley and Massaquoi, 1992). We believe that the technical advantages of in vivo microdialysis will continue to prove useful in unraveling these and other questions about the mechanisms of sleep cycle control.

\section{REFERENCES}

Adell A, Artigas F (1991) Differential effects of clomipramine given locally or systemically on extracellular 5-hydroxytryptamine in raphe nuclei and frontal cortex. Naunyn Schmiedebergs Arch Pharmacol 343:237 244

Adell A, Carceller A, Artigas F (1993) In vivo brain dialysis study of the somatodendritic release of serotonin in the raphe nuclei of the rat: effects of 8-hydroxy-2-(di-n-propylamino) tetralin. I Neurochem 60:1673-1681.

Adrien J, Hamon M (1989) Involvment of 5-HT3 and 5-HT1A receptors in the control of sleep-wakefulness cycles in the cat. Sleep Res 18:29.

Ahlenius S, Larsson K, Svensson L, Hjorth S, Carlsson A, Lindberg P, Wikstrom H, Sanchez D, Arvidsson LE, Hacksell U, Nilsson JLG (1981) Effects of a new type of 5-HT receptor agonist on male rat sexual behaviour. Pharmacol Biochem Behav 15:785-792.
Arvidsson LE, Hacksell U, Nilsson JLG, Hjorth S, Carlsson A, Lindberg P, Sanchez D, Wikstrom H (1981) 8-Hydroxy-2-(di-n-propylamino) tetralin, a new centrally acting 5-HT receptor agonist. J Med Chem 24:921.

Auerbach SB, Minzenberg MJ, Wilkinson LO (1989) Extracellular serotonin and 5-hydroxyindolacetic acid in hypothalamus of the unanesthetized rat measured by in vivo dialysis coupled to high performance liquid chromatography with electrochemical detection: dialysate serotonin reflects neuronal release. Brain Res 499:281-290.

Berman AL (1968) The brain stem of the cat. Madison: University of Wisconsin.

Bill DJ, Knight M, Forster EA, Fletcher A (1991) Direct evidence for an important species difference in the mechanism of 8-OH-DPAT induced hypothermia. Br J Pharmacol 103:1857-1864.

Blundell JE (1977) Is there a role for serotonin (5-hydroxytryptaminc) in feeding? Int J Obesity 1:15-42.

Bonvento G, Scatton B, Claustre Y, Rouquier L (1992) Effect of local injection of 8-OH-DPAT into the dorsal or median raphe nuclei on extracellular levels of serotonin in serotonergic projection areas. Neurosci Lett 137:101-104.

Carboni E, Di Chiara G (1989) Serotonin release estimated by transcortical dialysis in freely moving rats. Neuroscience 32:637-645.

Cespuglin R, Faradji H, Gomez ME, Jouvet M (1981) Single unit recording in the nuclei raphe dorsalis and magnus during the sleep-waking cycle of semi-chronic prepared cats. Neurosci Lett 24:133-138.

Coccaro EF (1992) Impulsive aggression and central serotoninergic system function in humans: an example of a dimensional brain-behavior relationship. Int Clin Psychopharmacol 7:3-12.

Crespi F, Garratt JC, Sleight AJ, Marsden CA (1990) In vivo evidence that 5-hydroxytryptamine (5-HT) neuronal firing and release are not necessarily correlated with 5-HT metabolism. Neuroscience 35:139.

De St. Hilaire-Kafi S, Hjorth S, Gaillard JM (1987) Effect of the 8-OHDPAT on the sleep-waking cycle in the rat. In: Brain 5-HT1a receptors, behavioural and pharmacology. Ellis Horwood Series in Biomedicine (Dourish CT, Ahlenius S, Hutson PH, eds), pp 135-139. New York: $\mathrm{VCH}$.

Gilbert F, Dourish CT, Brazell C McClue S, Stahl SM (1988) Relationship of increased food intake and plasma ACTH levels to 5-HT1a receptor activation in rats. Psychoneuroendocrinology 13:471-478.

Glennon RA, Naiman NA, Pierson ME, Titeler M, Lyon RA, Weisberg E (1988) NAN-190: an arylpiperazine analog that antagonizes the stimulus effects of the 5-HT1a agonist 8-hydroxy-2-(di-n-propylamino)tetralin (8-OH-DPAT). Eur J Pharmacol 154:339.

Gozlan H, El Mestikawy S, Pichat L, Glowinski J, Hamon M (1983) Identification of presynaptic serotonin autoreceptors using a new ligand: ${ }^{3} \mathrm{H}-\mathrm{PAT}$. Nature 305:140.

Higgins GA, Bradbury AJ, Jones BJ, Oakley NR (1988) Behavioural and biochemical consequences following aclivation of 5-HT1-like and GABA receptors in the dorsal raphe nucleus of the rat. Neuropharmacology 27:993-1001.

Hobson JA, McCarley RW, Wyzinski PW (1975) Sleep cycle oscillation: reciprocal discharge by two brain stem neuronal groups. Science 189:55-58.

Hodgkiss JP, Dawson IM, Kelly JS (1992) An intracellular study of the action of NAN-190 on neurons in the dorsal raphe nucleus of the rat. Brain Res 576:157-161.

Honda T, Semba K (1994) Serotonergic synaptic input to cholinergic neurons in the rat mesopontine tegmentum. Brain Res 47:299-306.

Houdouin F, Cespuglio R, Gharib A, Sarda N, Jouvet M (1991) Detection of the release of 5-hydroxyindole compounds in the hypothalamus and the $\mathrm{n}$. raphe dorsalis through the sleep-waking cycle and during stressful situations in the rat: a polygraphic and voltammetric approach. Exp Brain Res 85:153-162.

Hutson PH, Dourish CT, Curzon G (1986) Neurochemical and hehavioural evidence for mediation of the hyperphagic action of 8-OH-DPAT by 5-HT cell body autoreceptors. Eur J Pharmacol 129:347-352.

Imeri L, De Simoni MG, Giglio R, Clavenna A, Mancia M (1994) Changes in the serotoninergic system during the sleep-wake cycle: simultaneous polygraphic and voltammetric recordings in hypothalamus using a telemetry system. Neuroscience 58:353-358.

Jacobs BL, Fornal CA (1993) 5-HT and motor control: a hypothesis. Trends Neurosci 16:346-352.

Kao CY (1966) Tetrodotoxin, saxitoxin and their significance in the study of exitation phenomena. Pharmacol Rev 18:997. 
Kodama T, Takahashi Y, Honda Y (1990) Enhancement of acetylcholine release during paradoxical sleep in the dorsal tegmental field of the cat brain stem. Neurosci Lett 114:277.

Le Bars D (1988) Serotonin and pain. In: Neuronal serotonin (Osborne NN, Hamon M, eds), pp 171-229. New York: Wiley.

Lebrand C, Lainey E, Cantalloube C, Laporte AM, Fattacini CM, Hamon M, Adrien J (1994) Probable involvment of postsynaptic 5-HT1a receptors in the effects of 5-HT1a ligands on sleep and wakefulness. J Sleep Res 3:142.

Leonard CS, Llinas R (1994) Serotonergic and cholinergic inhibition of mesopontine cholinergic neurons controlling REM sleep: an in vitro electrophysiological study. Neuroscience 59:309-330.

Leonard TO, Lydic R (1995) Nitric oxide synthase inhibition decreases pòntine acetylcholine release. NeuroReport 6:1525-1529.

Luebke JI, Greene RW, Semba K, Kamondi A, McCarley RW, Reiner PB (1992) Serotonin hyperpolarizes cholinergic low threshold burst neurons in the rat laterodorsal tegmental nuclei in vitro. Proc Natl Acad Sci USA 89:743-717.

Lydic R, Baghdoyan HA (1993) Pedunculopontine stimulation alters respiration and increases $\mathrm{ACh}$ release in the pontine reticular formation. AII J Pliysiol 264:R544-R554.

Lydic R, McCarley RW, Hobson JA (1987) Serotonin neurons and sleep. II. Time course of dorsal raphe discharge, PGO waves and behavioral states. Arch Ital Biol 126:1-28.

McCarley RW, Hobson JA (1975) Neuronal excitability modulation over the sleep cycle: a structural and mathematical model. Science 189:58-60.

McCarley RW, Massaquoi SG (1992) The limit cycle reciprocal interaction model of REM cycle control: new neurobiological structure. J Sleep Res 1:132-137.

McEntee WJ, Crook TH (1991) Serotonin, memory and the aging brain. Psychopharmacology 103:143-118.

McGinty D, Harper RM (1976) Dorsal raphe neurons: depression of firing during sleep in cats. Brain Res 101:569-575.

McGinty D, Szymusiak R (1990) Keeping cool: a hypothesis about the mechanisms and functions of slow wave sleep. Trends Neurosci 13:480-487.

Meston CM, Gorzalka BB (1992) Psychoactive drugs and human sexual behavior: the role of serotonergic activity. J Psychoactive Drugs 24:1-40.

Middlemiss DN, Fozard JR (1983) 8-Hydroxy-2-(di-n-propylamino)tetralin discriminates between subtypes of the 5-HT1 recognition site. Eur J Pharmacol 90:151.

Mitani A, Ito K, Hallanger AE, Wainer BH, Kataoka K, McCarley RW (1988) Cholinergic projections from the laterodorsal and pedunculopontine tegmental nuclei to the pontine gigantocellular tegmental field in the cat. Brain Res 451:397-402.

Montange M, Calas A (1988) Serotonin and endocrinology: the pituitary. In: Neuronal serotonin (Osborne NN, Hamon M, eds), pp 271-303. New York: Wiley.

Monti JM, Jantos H (1992) Dose-dependent effects of the 5-HT1a receptor agonist 8-OH-DPAT on sleep and wakefulness in the rat. J Sleep Res 1:169-175.

Monti JM, Pineyro G, Orellana C, Boussard M, Jantos H, Labraga P, Olivera S, Alvarino F (1990) 5-HT receptor agonists 1-(2,5-dimethoxy4-iodophenyl)-2-aminopropane (DOI) and 8-OH-DPAT increase wakefulness in the rat. Biogen Amines 7:145-151.

Mos J, Olivier B, Poth M, Van Oorschot R, Van Aken H (1993) The effects of dorsal raphe administration of eltoprazine, TFMPP and 8. OH DPAT on resident intruder aggression in the rat. Eur $\mathbf{J}$ Pharmacol 238:411-415.

Myers RD (1980) Hypothalamic control of thermoregulation. In: Handbook of the hypothalamus, Vol 3 (Morgane PJ, Panksepp J, eds), pp 83-210. New York: Marcel Dekker.

Nicolaidis S (1986) Serotonergic system, feeding and body weight regulation. London: Academic.

Nishikawa T, Scatton B (1985) Inhibitory influence of GABA on central serotonergic transmission: raphe nuclei as the neuroanatomical site of the GABAergic inhibition of cerebral serotonergic neurons. Brain Res 331:91-103.
Nitz D, Siegel JM (1993) GABA release in the mesopontine central grey as a function of sleep state. Sleep Res 22:447.

O'Connor JJ, Kruk ZL (1992) Pharmacological characteristics of 5 -hydroxytryptamine autoreceptors in rat brain slices incorporaling the dorsal raphe or the suprachiasmatic nucleus. $\mathrm{Br} \mathrm{J}$ Pharmacol 106:524-532.

Olivier B, Mos J (1992) Rodent models of aggressive behavior and serotonergic drugs. Prog Neuropsychopharmacol Biol Psychiatry 16:847-874.

Penington NJ, Kelly JS, Fox AP (1993) Whole-cell recordings of inwardly rectifying $\mathrm{K}^{+}$currents activated by $5 \mathrm{HT}_{1 \mathrm{~A}}$ receptors on dorsal raphe neurones of the adult rat. J Physiol (Lond) 469:387-405.

Pickcl VM, Joh TII, Reis DJ (1977) A serotonergic innervation of noradrenergic neurons in the nucleus coeruleus: demonstration by immunocytochemical localization of the transmitter specific enzymes tyrosine and tryptophan hydroxylase. Brain Res 131:197-214.

Portas CM, McCarley RW (1994) Behavioral state related changes of extracellular serotonin concentration in the dorsal raphe nucleus: a microdialysis study in the freely moving cat. Brain Res 648:306-312.

Quattrochi JJ, Mamelak AN, Binder D, Williams J, Hobson JA (1993) Dosc-rclated suppression of REM sleep and PGO waves by the serotonin agonist eltoprazine. Neuropsychopharmacology 8:7-13.

Robinson TE, Justice JB (1991) Microdialysis in the neuroscience: technique in the behavioral and neural sciences, Vol 7 (Justice JP, ed). Amsterdam: Elsevier.

Sanford LD, Ross RJ, Seggos AE, Morrison AR, Ball WA, Mann GI. (1994) Central administration of two 5-HT receptor agonists: effect on REM sleep initiation and PGO waves. Pharmacol Biochem Behav 49:93-100.

Semba K (1993) Aminergic and cholinergic afferents to REM sleep induction regions of the pontine reticular formation in the rat. J Comp Neurol 330:543-556.

Shiromani PJ, Malik MR, McCarley RW (1992) Topographical distribution of noradrenergic, serotonergic and cholinergic perikarya in the feline pons: a 3-D perspective. Sleep Res 21:77.

Soubrie P (1988) Serotonin and behaviour, with special regard to animal models of anxiety, depression and waiting ability. In: Ncuronal scrotonin (Osborne NN, Hamon M, eds), pp 255-270. New York: Wiley.

Sprouse JS, Aghajanian GK (1987) Electrophysiological responses of serotonergic dorsal raphe neurons to 5-H'I'1A and 5-HT1B agonists. Synapse 1:3-9.

Steriade M, McCarley RW (1990) Brainstem control of wakefulness and sleep. New York: Plenum.

Steriade M, Datta S, Pare D, Oakson G, Curro-Dossi R (1990) Neuronal activities in brain stem cholinergic nuclei related to tonic activation processes in thalamocortical systems. J Neurosci 10:2541-2559.

Stuart GJ, Sakmann B (1994) Active propagation of somatic action potentials into neocortical pyramidal cell dendrites. Nature 367:69-72.

Thornton EW, Goudie AJ (1978) Evidence for the role of serotonin in the inhibition of specific motor responses. Psychopharmacology 60:73-79.

Trulson ME, Jacobs BL (1979) Raphe unit activity in freely moving cats: correlation with level of behavioural arousal. Brain Res 163:135-150.

Wiklund L, Leger L, Persson M (1981) Monoamine cell distribution in the cat brain stem: a fluorescence histochemical study with quantification of indolaminergic and locus coeruleus cell groups. J Comp Neurol 203:613-647.

Wilkinson LO, Auerbach SB, Jacobs BL (1991) Extracellular serotonin levels change with behavioral state but not with pyrogen-induced hyperthermia. J Neurosci 11:2732-2741.

Williams JH, Azmitia EC (1981) Hippocampal serotonin re-uptake and nocturnal locomotor activity after microinjections of 5,7-DHT in the fornix-fimbria. Brain Res 207:95-107.

Williams JA, Reiner PB (1993) Noradrenaline hyperpolarizes identified rat mesopontine cholinergic neurons in vitro. J Neurosci 13:3878-3883.

Williams JT, Colmers WF, Pan ZZ (1988) Ligand- and voltage-activated inwardly rectifying currents in dorsal raphe neurons in vitro. $\mathbf{J}$ Neurosci 8:3499-3506. 